\title{
Radiation Synthesis of Silver Nanoparticles/Chitosan for Controlling Leaf Fall Disease on Rubber Trees Causing by Corynespora cassiicola
}

\author{
Le Thi An Nhien, ${ }^{1,2}$ Nguyen Duc Luong, ${ }^{2}$ Le Thi Thuy Tien, ${ }^{2}$ and Le Quang Luan $\mathbb{D}^{3}$ \\ ${ }^{1}$ Dong Nai Hi-Tech and Biotechnology Park, Xuan Duong Ward, Cam My District, Dong Nai Province, Vietnam \\ ${ }^{2}$ Ho Chi Minh City University of Technology, Vietnam National University Ho Chi Minh City, 268 Ly Thuong Kiet Street, \\ Ward 14, District 10, Ho Chi Minh City, Vietnam \\ ${ }^{3}$ Biotechnology Center of Ho Chi Minh City, 2374 Highway 1, Trung My Tay Ward, District 12, Ho Chi Minh City, Vietnam \\ Correspondence should be addressed to Le Quang Luan; lequangluan@gmail.com
}

Received 23 February 2018; Accepted 28 March 2018; Published 6 May 2018

Academic Editor: Piersandro Pallavicini

Copyright (C) 2018 Le Thi An Nhien et al. This is an open access article distributed under the Creative Commons Attribution License, which permits unrestricted use, distribution, and reproduction in any medium, provided the original work is properly cited.

\begin{abstract}
Silver nanoparticles (AgNPs) were successfully prepared by $\gamma$-rays irradiation of solution containing 1.0-10 mM of silver nitrate and $1 \%$ chitosan. The optical characteristics and particles sizes of AuNPs were determined by UV-Vis spectra and TEM images, respectively. The size of AgNPs increased by the increase of silver concentration or the decrease of chitosan molecular weight in irradiated solution. The in vitro test showed that AgNPs inhibited the growth of Corynespora cassiicola on rubber-leaf extract media with the inhibitory efficiency of $52.1-100 \%$ by treatment of AgNPs with particle size from 15 to $5 \mathrm{~nm}$, respectively. In addition, antifungal activity was found to reach $\sim 100 \%$ by the addition of $90 \mathrm{ppm}$ AgNPs. The in vivo foliar treatment of AgNPs on 9month-old rubber plants showed that the treatment with 2.5-12.5 ppm AgNPs on tested plants after inoculation by spraying with $C$. cassiicola spores enhanced the rate of non-disease-infected plants from 6.0 to $93.3 \%$, respectively, compared to the untreated control. The inhibition effect of AgNPs on fungal growth of C. cassiicola mycelial was also elucidated via SEM images. The AgNPs/chitosan synthesized by $\gamma$-irradiation is potentially promising to use as a fungicidal product for treating $C$. cassiicola, a serious pathogen fungus on rubber trees.
\end{abstract}

\section{Introduction}

Rubbers (Hevea brasiliensis) are long day-industrial trees and provide raw materials for many industrial sectors. They possessed very high economic values and have already brought many profits for agriculture. According to General Statistics Office of Vietnam in 2017, Vietnam is now having the third ranking with rubber tree plantation area reaching 971.6 thousand hectares and the total production of rubber latex reached 1,086 thousand tons. However, rubber growers are now facing many difficulties due to the outspread of many diseases caused by microorganisms, among which, leaf fall disease caused by C. cassiicola is now severely affecting rubbers growth and yield [1]. C. cassiicola disease was first observed on rubber trees in Sierra Leone (Affrica) in 1936. More cases were reported in India and Malaysia in 1961;
Nigeria in 1968; Thailand, Srilanca, and Indonesia in 1985; Brazil and Bangladesh in 1988 [2, 3]. Though leaf fall disease in rubbers was only observed in Vietnam from August 1999, the disease was spread rapidly and widely in many provinces in Southeast, Central Highlands, and Central Coast of Vietnam. Prevention of leaf fall disease is now still a challenging problem due to the lacking of specific fungicides while growers are now using many chemical derived products that would cause various negative impacts on the environment as well as rubber quality. Chitosan at low molecular weight has been proved as a natural, safe, and effective product for agriculture [4]. Many researches have been already reported that besides having growth enhancing effects on plants, chitosan also provides plants with the ability to prevent many pathogenic infections by boosting the immunity system of plant cells, so called phytoalexin effects [5-7]. In addition, 
silver nanoparticles (AgNPs) were extensively studied and widely used for a long time due to their unique properties such as bacterial and fungal inhibition and odor removal at low concentration and safe to human and the environment. The antifungal effect of AgNPs stabilized in chitosan has been studied on pathogen fungi such as Colletotrichum [8] and Corticium salmonicolor [9]. Moreover, irradiation with $\gamma$-rays using a Co-60 source was considered as an effective method for the synthesis of noble metal nanoparticles [10]. The advantages of irradiation method were energy, premises, and materials saving, environmentally friendly, and so forth. In particular, the process can be conducted at ambient temperature and favorably scaled up to mass production with reasonable price [10-12]. This research aimed to synthesize AgNPs/chitosan product that is safe to human and effective in elimination of leaf fall disease caused by C. cassiicola on rubber trees.

\section{Materials and Methods}

2.1. Materials. Silver nitrate powder $\left(\mathrm{AgNO}_{3}\right)$ in pure grade was supplied by Merck Co., Germany. Chitosan with degree of deacetylation of $80 \%$ was purchased from Loyou Chemical Co., Ltd., Japan. Pathogenesis fungus, namely, Corynespora cassiicola, was a gift from Rubber Research Institute of Vietnam.

2.2. Synthesis of AgNPs/Chitosan by $\gamma$-Ray Irradiation. Silver nitrate solutions at different concentrations of $1.0 ; 2,5 ; 5.0$; and $10 \mathrm{mM}$ dissolved in $1 \%$ chitosan solution were stored in glass bottles and irradiated at different doses from 8 to $28 \mathrm{kGy}$ using $\gamma$-rays from a Co-60 source (Gamma Chamber 5000, BRIT, India) with a dose rate of $3 \mathrm{kGy} / \mathrm{h}$. AgNPs colloidal solutions synthesized by $\gamma$-ray irradiation were used for further experiments.

2.3. Characterization of Silver Nanoparticles/Chitosan. The $\mathrm{UV}-\mathrm{Vis}$ spectra of resultant AgNPs solution samples which were diluted to $0.1 \mathrm{mM}$ calculated as $\mathrm{Ag}^{+}$concentration using deionized water were measured on an UV-2401PC, Shimadzu, Japan $[9,11,13]$. The AgNPs size and size distribution were determined by TEM images on a JEM 1400, JEOL, Japan, followed the method described by Li et al. [11] and Phu et al. [9].

2.4. Antifungal Activity of AgNPs/Chitosan. Rubber-leaf extract media were used for $C$. cassiicola culture. The rubberleaf extract was prepared by boiling $200 \mathrm{~g}$ of fresh rubber leaves (free disease) in $1000 \mathrm{ml}$ distilled water for 45 minutes and followed by filtering to remove residue and adjusting $\mathrm{pH} \sim 6.5$. One liter of rubber-leaf extract was mixed with $20 \mathrm{~g}$ agar and supplemented with AgNPs at different particle sizes 5; 10; and $15 \mathrm{~nm}$, and AgNPs concentration varied from 10 to $90 \mathrm{ppm}$ before autoclaving at $121^{\circ} \mathrm{C}, 1 \mathrm{~atm}$ for $20 \mathrm{~min}$. Fungal samples with diameter $\sim 4 \mathrm{~mm}$ were cultured on the center of rubber-leaf extract agar plates and incubated in dark condition at $28 \pm 2^{\circ} \mathrm{C}$. Five replicate plates were applied for each concentration or particle size text and all experiments were repeated in triplicate. The colony diameters of $C$. cassiicola in the medium were measured every 24 hours and the antifungal efficiency of AgNPs/chitosan was calculated using the following:

$$
\text { Inhibition efficiency }(\%)=100 \times \frac{D-d}{D},
$$

where $D(\mathrm{~mm})$ and $d(\mathrm{~mm})$ are fungal colony diameters on the medium with or without supplemented with AgNPs, respectively.

2.5. Scanning Electron Microscopy (SEM) Analysis. Approximately $5 \mathrm{ml}$ solution containing 7.5 and $12.5 \mathrm{ppm}$ of AgNPs was spread on fully developed C. cassiicola mycelia grown on rubber-leaf extract agar media by a sprayer. The control was applied by distilled water in the same volume. All applications were done with the time interval of four days and were incubated at room temperature. The SEM images of treated samples were observed on a FE-SEM S4800, Hitachi Co., Tokyo, Japan, at an accelerating voltage of $10 \mathrm{kV}$.

2.6. In Vivo Fungicidal Effect of AgNPs against C. cassiicola on Rubber Plants. Nine-month-old rubber trees (diseasefree) were grown and maintained in a greenhouse before the experiment. For testing the elimination effect of AgNP on fungal pathogen C. cassiicola, leaves of 210 disease-free rubber trees ( 30 plants for each treatment) were first wounded before inoculating with $300 \mathrm{~mL}$ C. cassiicola solution containing $10^{4}$ fungal spores $/ \mathrm{mL}$. The control ones were foliar sprayed with the same volume of distilled water. After infection about 7 days, the number of disease-infected plants reached to about $50 \%$ for all of the treatments; $50 \mathrm{~mL}$ AgNPs solution with concentrations of $2.5,5,7.5,10$, and $12.5 \mathrm{ppm}$ was foliar sprayed every 3 days up to 3 times. The number of diseaseinfected plants and the number of disease-infected leaves in each treatment were observed after 7 days within 28 days of experiment. Plant and leaf disease incidence (DI) were expressed in percentage (\%) and calculated by using the following [14]:

$$
\begin{aligned}
\text { Plant DI }(\%)= & \left(\frac{\text { Number of infected plants }}{\text { Total number of plants assessed }}\right) \\
& \times 100 \\
\text { Leaf DI }(\%)= & \left(\frac{\text { Number of infected leaves }}{\text { Total number of leafs assessed }}\right) \\
& \times 100 .
\end{aligned}
$$

Each experiment was carried out in triplicate and data were statistically analyzed using the analysis of variance (ANOVA) test. The mean values were compared using Duncan's multiple range test at a probability level at 5\%.

\section{Results and Discussion}

3.1. Radiation Synthesis of Silver Nanoparticles/Chitosan by $\gamma$ Ray Irradiation. In this experiment, the solution containing silver ion concentrations of $1 ; 2.5 ; 5$; and $10 \mathrm{mM}$ stabilized in $1 \%$ chitosan with molecular weight $(\mathrm{Mw})$ about $550 \mathrm{kDa}$ 
TABLE 1: Effect of AgNPs concentration on elimination of C. cassiicola after being inoculated in rubber plants.

\begin{tabular}{|c|c|c|c|c|c|c|c|c|c|c|}
\hline \multirow[b]{2}{*}{ AgNPs, ppm } & \multicolumn{5}{|c|}{ Plant DI (\%) } & \multicolumn{5}{|c|}{ Leaf DI (\%) } \\
\hline & $\begin{array}{c}0 \\
\mathrm{DAT}^{* * *}\end{array}$ & $\begin{array}{c}7 \\
\text { DAT }\end{array}$ & $\begin{array}{c}14 \\
\text { DAT }\end{array}$ & $\begin{array}{c}21 \\
\text { DAT }\end{array}$ & $\begin{array}{c}28 \\
\text { DAT }\end{array}$ & $\begin{array}{c}0 \\
\text { DAT }\end{array}$ & $\begin{array}{c}7 \\
\text { DAT }\end{array}$ & $\begin{array}{c}14 \\
\text { DAT }\end{array}$ & $\begin{array}{c}21 \\
\text { DAT }\end{array}$ & $\begin{array}{c}28 \\
\text { DAT }\end{array}$ \\
\hline 0 checking ${ }^{*}$ & $0^{\mathrm{a}}$ & $0^{\mathrm{a}}$ & $0^{\mathrm{a}}$ & $0^{\mathrm{a}}$ & $0^{\mathrm{a}}$ & $0^{\mathrm{a}}$ & $0^{\mathrm{a}}$ & $0^{\mathrm{a}}$ & $0^{\mathrm{a}}$ & $0^{\mathrm{a}}$ \\
\hline $0\left(_{\text {control }}\right)^{* *}$ & $50.0^{\mathrm{b}}$ & $100^{\mathrm{e}}$ & $100^{\mathrm{e}}$ & $100^{\mathrm{e}}$ & $100^{\mathrm{e}}$ & $50.3^{\mathrm{b}}$ & $73.0^{\mathrm{f}}$ & $100^{\mathrm{e}}$ & $100^{\mathrm{e}}$ & $100^{\mathrm{e}}$ \\
\hline 2.5 & $50.0^{\mathrm{b}}$ & $46.7^{\mathrm{d}}$ & $43.3^{\mathrm{d}}$ & $36.7^{\mathrm{d}}$ & $30.0^{\mathrm{e}}$ & $51.5^{\mathrm{b}}$ & $47.8^{\mathrm{e}}$ & $44.4^{\mathrm{d}}$ & $36.3^{\mathrm{e}}$ & $31.5^{\mathrm{c}}$ \\
\hline 5 & $50.0 \mathrm{~b}^{\mathrm{b}}$ & $43.3^{\mathrm{cd}}$ & $40.0^{\mathrm{cd}}$ & $33.3^{\mathrm{cd}}$ & $26.7^{\mathrm{de}}$ & $49.8^{\mathrm{b}}$ & $43.5^{\mathrm{d}, \mathrm{e}}$ & $40.5^{\mathrm{d}}$ & $34.3^{\mathrm{d}, \mathrm{e}}$ & $28.3^{c}$ \\
\hline 7.5 & $53.3^{\mathrm{b}}$ & $40.0^{\mathrm{bcd}}$ & $36.7^{\mathrm{cd}}$ & $30.0^{\mathrm{cd}}$ & $23.3^{\mathrm{d}}$ & $50.2^{\mathrm{b}}$ & $40.2^{\mathrm{c}, \mathrm{d}}$ & $35.3^{\mathrm{c}}$ & $30.9^{\mathrm{c}, \mathrm{d}}$ & $24.5^{\mathrm{c}}$ \\
\hline 10 & $53.3^{\mathrm{b}}$ & $36.7^{\mathrm{bc}}$ & $33.3^{b c}$ & $26.7^{\mathrm{c}}$ & $13.3^{\mathrm{c}}$ & $51.7^{\mathrm{b}}$ & $36.1^{b, c}$ & $33.1^{\mathrm{c}}$ & $26.7^{\mathrm{c}}$ & $13.2^{\mathrm{b}}$ \\
\hline 12.5 & $50.0^{\mathrm{b}}$ & $33.3^{\mathrm{b}}$ & $26.7^{\mathrm{b}}$ & $16.7^{\mathrm{b}}$ & $6.7^{\mathrm{b}}$ & $50.2^{\mathrm{b}}$ & $33.6^{\mathrm{b}}$ & $28.1^{\mathrm{b}}$ & $16.6^{\mathrm{b}}$ & $6.7^{\mathrm{ab}}$ \\
\hline
\end{tabular}

${ }^{*}$ Checking: plant without treatment of fungal spore and AgNPs. ${ }^{* *}$ Control: plants were infected by fungus spores before treating with only distilled water. *** DAT: day after treatment; mean values followed by the same letter within a column are not statistically different according to Duncan's multiple range test at $P<0.05$.

was irradiated at $8,12,16$, and $28 \mathrm{kGy}$, respectively. Huang et al. [15] reported that different AgNPs sizes would lead to various maximum absorbance wavelengths $\left(\lambda_{\max }\right)$ and peak intensities. The value of $\lambda_{\max }$ shifted to the longer wavelength with the increase of AgNPs size $[9,15,16]$. It can be seen from Figure 1 that the peak intensity values of irradiated samples in UV-Vis spectra decreased from 1.26 to 1.02 by the increase of the silver concentration in irradiated sample from 1 to $10 \mathrm{mM}$, while $\lambda_{\text {max }}$ values of these sample shifted from 397 to $405.5 \mathrm{~nm}$. In addition, the particle size estimated from TEM images of AgNPs samples after irradiation also increased from 5 to $10 \mathrm{~nm}$ when the sliver concentration increased from 1 to $10 \mathrm{mM}$, respectively. Many researchers reported that the antimicrobial activities of AgNPs increased by the decrease of particle size [17]. Thus, in order to synthesize AgNPs with desired size for different applications, selection of the initial $\mathrm{Ag}^{+}$concentration to prepare AgNPs is very necessary.

On the other hand, the effect of Mw of chitosan on particles size of AgNPs was also investigated. The results in Figure 2 showed that $\mathrm{Mw}$ of chitosan affected the size of AgNPs formed in irradiated samples and the decrease of chitosan Mw from 550 to $100 \mathrm{kDa}$ led to the increase of AgNPs size from 10 to $15 \mathrm{~nm}$. Though the mechanism of these effects was not yet fully understood, the increase of solution viscosity corresponding to the increase of chitosan $\mathrm{Mw}$ might have reduced the dynamic of AgNPs and prevented them from agglomeration to form bigger nanocluster.

3.2. In Vitro Antifungal Activities of AgNPs/Chitosan against $C$. cassiicola. For testing antifungal efficiency by particle size of AgNPs/chitosan sample, AgNPs with particles size of about 5, 10 , and $15 \mathrm{~nm}$ were used. It can be seen in Figures 3 and 4 that the small particle size has a stronger effect on the growth of C. cassiicola on rubber-leaf extracted media after 192 hours of incubation compared to the big ones. Particularly, the supplementation of $50 \mathrm{ppm}$ AgNPs with particles size $15 \mathrm{~nm}$ showed a strong inhibition effect on C. cassiicola with the diameter fungal colony only reaching $43.1 \mathrm{~mm}$ compared to $90 \mathrm{~mm}$ of the untreated control and the inhibition efficiency was calculated about $52.1 \%$. The antifungal efficiency increased to $70.6 \%$ when the particle size decreased to $10 \mathrm{~nm}$ and reached to almost $100 \%$ for $5 \mathrm{~nm}$ particle size. Thus, the antifungal efficiency against $C$. cassiicola increased by the decrease of AgNPs size. The same tendency was also reported previously by Carlson et al. [17]. In addition, Franci et al. [18] also pointed out that it is easier for AgNPs at smaller size to penetrate through cell walls and alter and inhibit the cell signaling pathways as well as DNA replication and damage of cell organs through oxidative reaction.

On the other hand, the antifungal activities of AgNPs have been proved to be increased by the increase of silver concentration $[9,19-21]$. In this study, AgNPs with size of $10 \mathrm{~nm}$ stabilized in $1 \%$ chitosan $(\mathrm{Mw} \sim 550 \mathrm{kDa}$ ) were used to evaluate the in vitro antifungal activities against $C$. cassiicola at different AgNPs concentrations. Results from Figures 5 and 6 indicated that, after 10 days of incubation, the growth inhibition against $C$. cassiicola on cultural media plates supplemented with 10 and $30 \mathrm{ppm}$ AgNPs with inhibition efficiencies from 6.3 to $18.5 \%$, respectively, was rather low. Meanwhile, the growth of C. cassiicola was clearly inhibited by an addition of $50 \mathrm{ppm}$ with the fungal colony diameter only $50 \mathrm{~mm}$ compared to that of $90 \mathrm{~mm}$ on the untreated control plates (inhibition efficiency $66.4 \%$ ). However, the inhibition activity of AgNPs increased when an additive concentration increased to $70 \mathrm{ppm}$ (inhibition efficiency 91.7\%) and the growth of $C$. cassiicola was completely inhibited when the silver concentration reached $90 \mathrm{ppm}$ with an inhibition efficiency of $\sim 100 \%$.

\subsection{In Vivo Antifungal Activities of AgNPs/Chitosan against} C. cassiicola. There are several reports suggesting the antimicrobial effect of AgNPs against bacteria and fungi $[9,22,23]$. However, up to now, there are rare reports in the literature on the in vivo studies of the effect of AgNPs against fungi on plants. In the present study, the antifungal effect of AgNPs against C. cassiicola was investigated directly on rubber plants. The AgNPs with concentrations of 2.5 to $12.5 \mathrm{ppm}$ were applied on the tested rubber plants via foliar application. Alternatively, the AgNP has been proved to be efficient in controlling the disease when sprayed after the infection caused by fungi. The results from Table 1 disclosed that the damage of rubber plants infected by C. cassiicola fungus could 

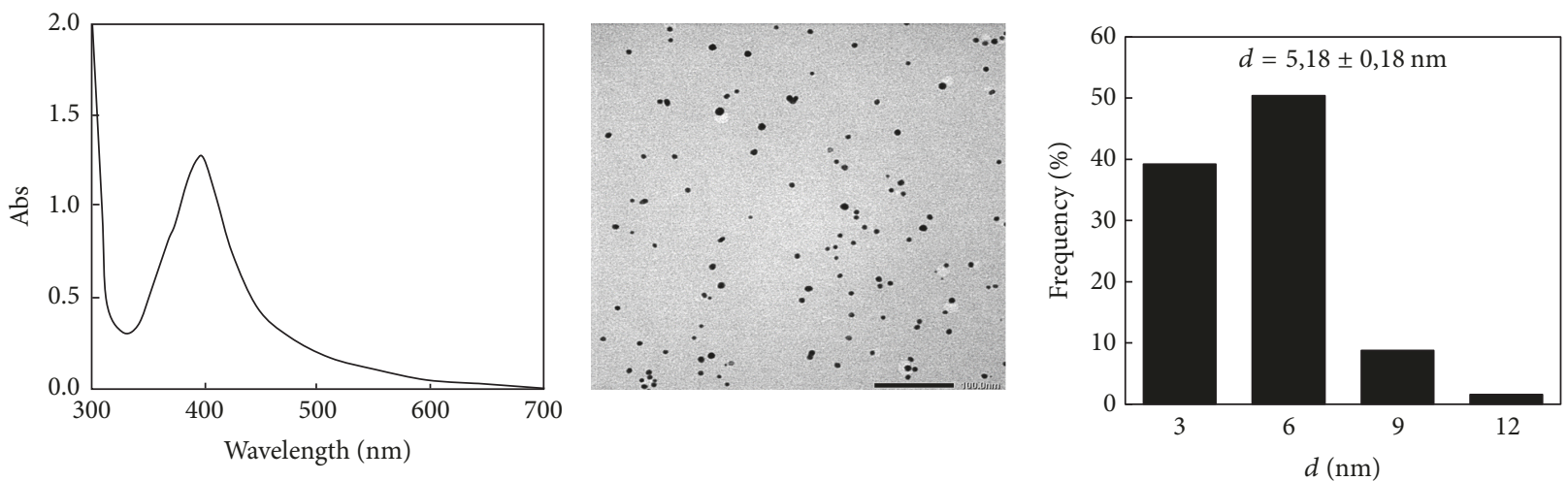

(a)
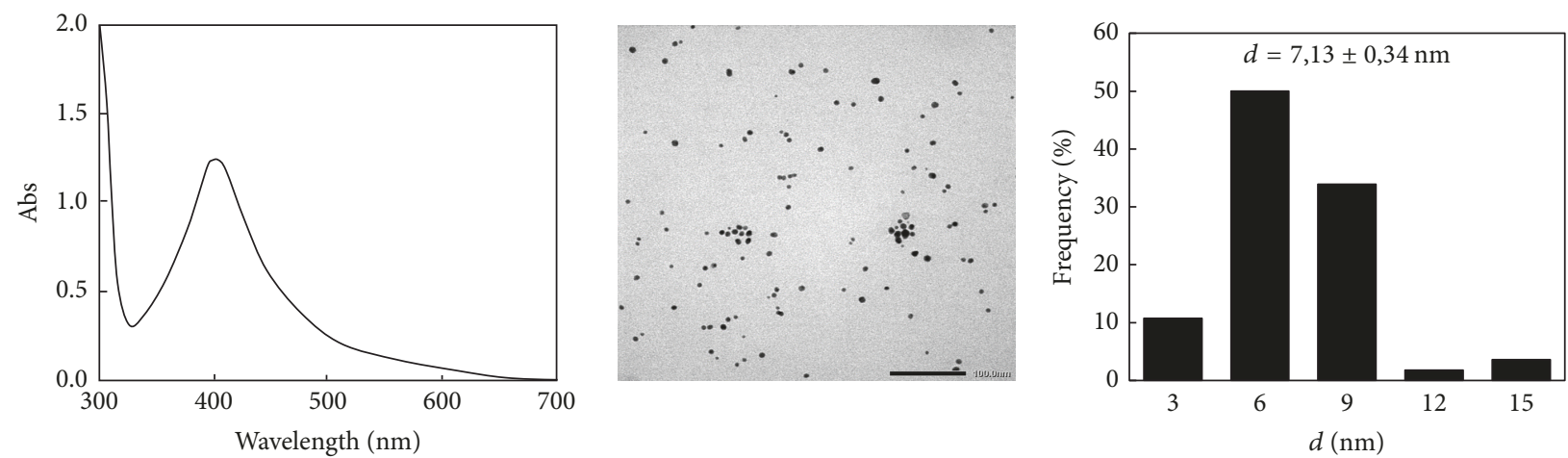

(b)
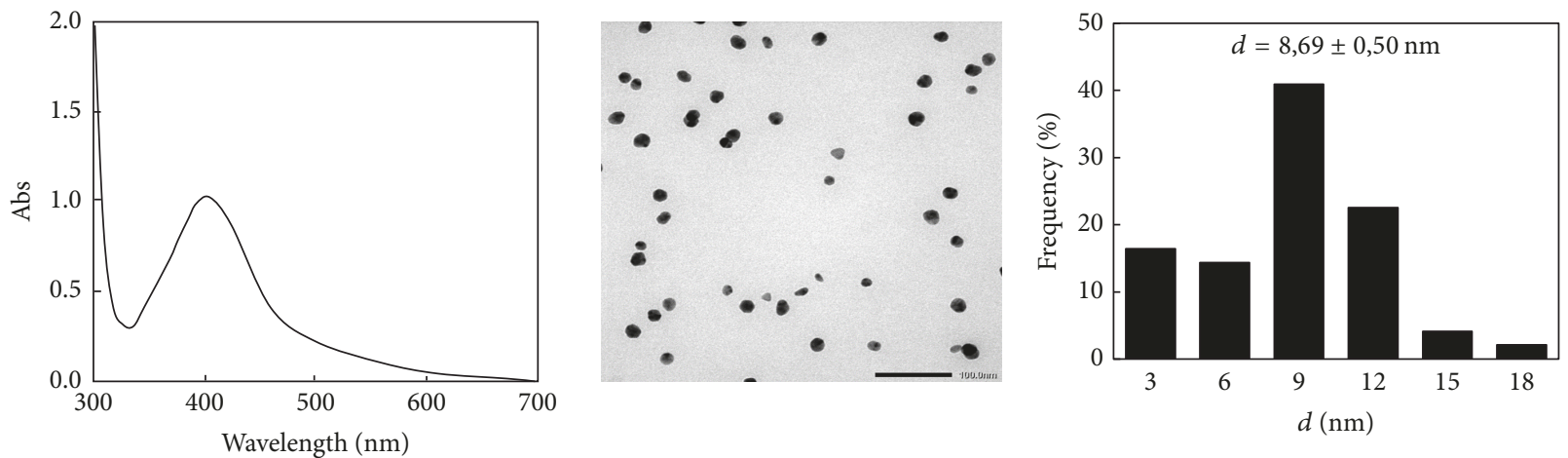

(c)
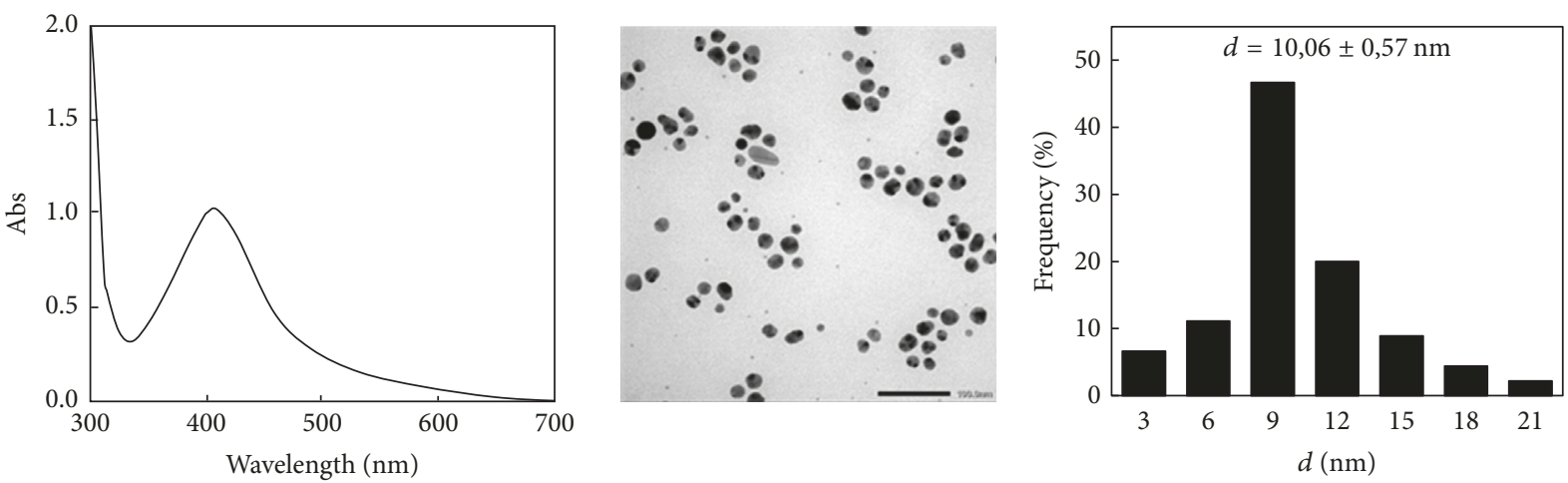

(d)

Figure 1: UV-Vis spectra (left side) and TEM images (middle side) and size distribution (right side) of $\mathrm{AgNPs} / \mathrm{chitosan}$ with $\mathrm{Ag}^{+}$ concentrations of 1 (a), 2.5 (b), 5 (c), and $10 \mathrm{mM}$ (d). 


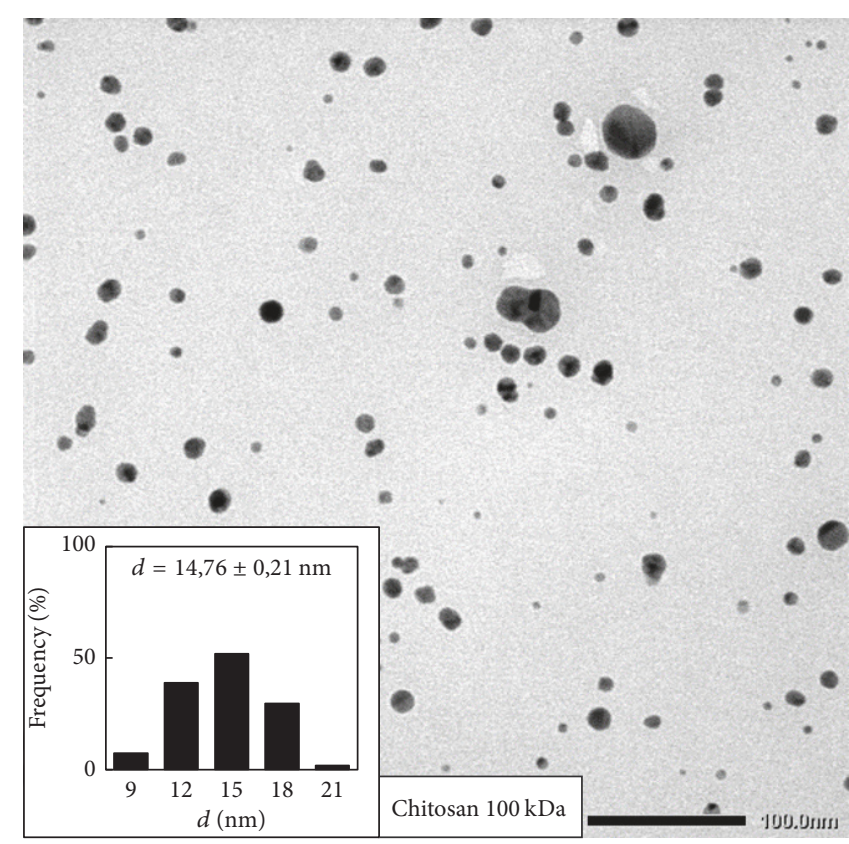

(a)

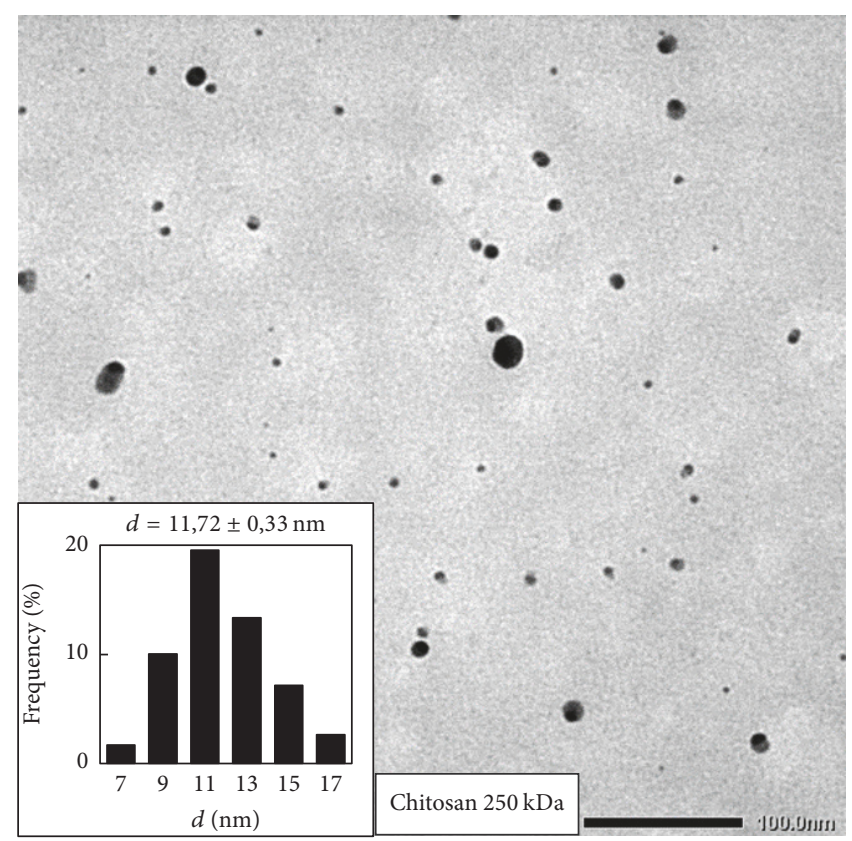

(b)

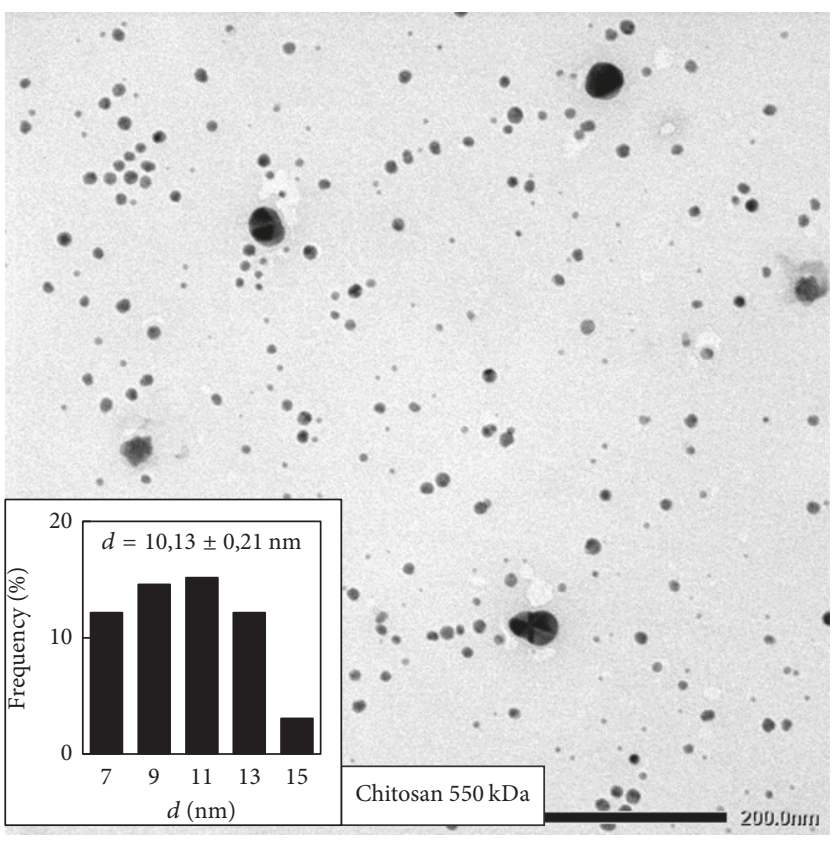

(c)

FIGURE 2: TEM images and size distribution of AgNPs stabilized by chitosan with Mw of 100 (a), 250 (b), and $550 \mathrm{kDa}$ (c).

be minimized by AgNP. In particular, plant DI decreased from 30 to $6.3 \%$ by treating AgNPs with the concentrations from 2.5 to $12.5 \mathrm{ppm}$, respectively. Furthermore, it can be seen from Table 1 and Figure 7 that the treatment of AgNPs also remarkably minimized the leave DI of infected plants and the rate of leave DI was inversely proportional to the treated concentration of AgNPs. These results are in agreement with the previous finding on Colletotrichum fungus species causing the anthracnose disease for pepper reported by Lamsal et al. [8]. The reasons can be explained that, after spraying, AgNPs may attach and kill the mycelium of pathogen fungus in plant tissue [24, 25].

The inhibition of AgNPs on C. cassiicola mycelial germination was analyzed via SEM in order to elucidate the effect of AgNPs on fungal growth. The SEM images in Figure 8 revealed that AgNPs clearly damaged the hyphae, while hyphae treated with water (control) appeared to remain intact. Fungal mycelia were sunken and damaged due to the effect of AgNPs. The fungal hyphae observing at the fourth day after the treatment of 7.5-12.5 ppm AgNPs showed 


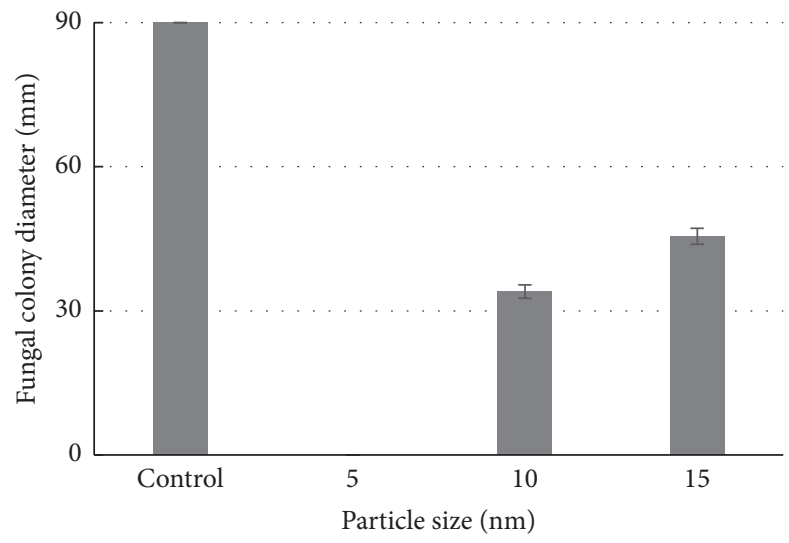

(a)

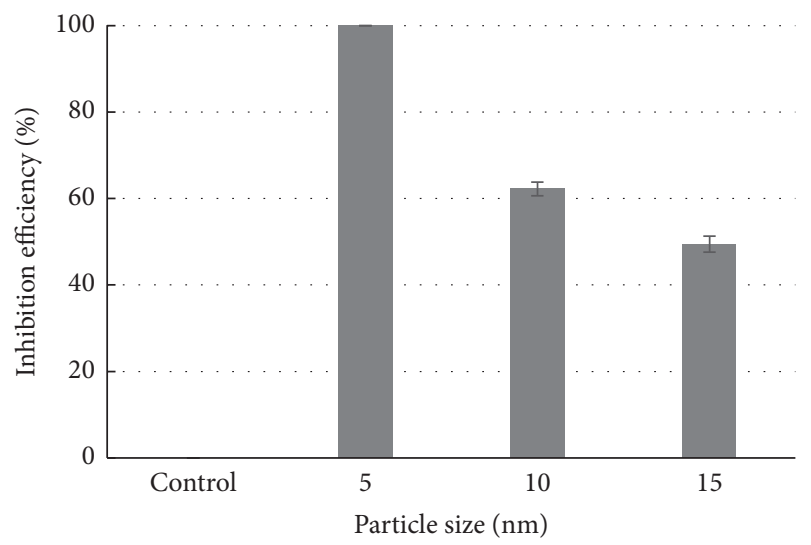

(b)

FIgURE 3: The antifungal activity against C. cassiicola of AgNPs with different particle sizes. (a) Diametter of fungal colony on rubber-leaf extract media after 192 hours incubation and (b) inhibition efficiency.
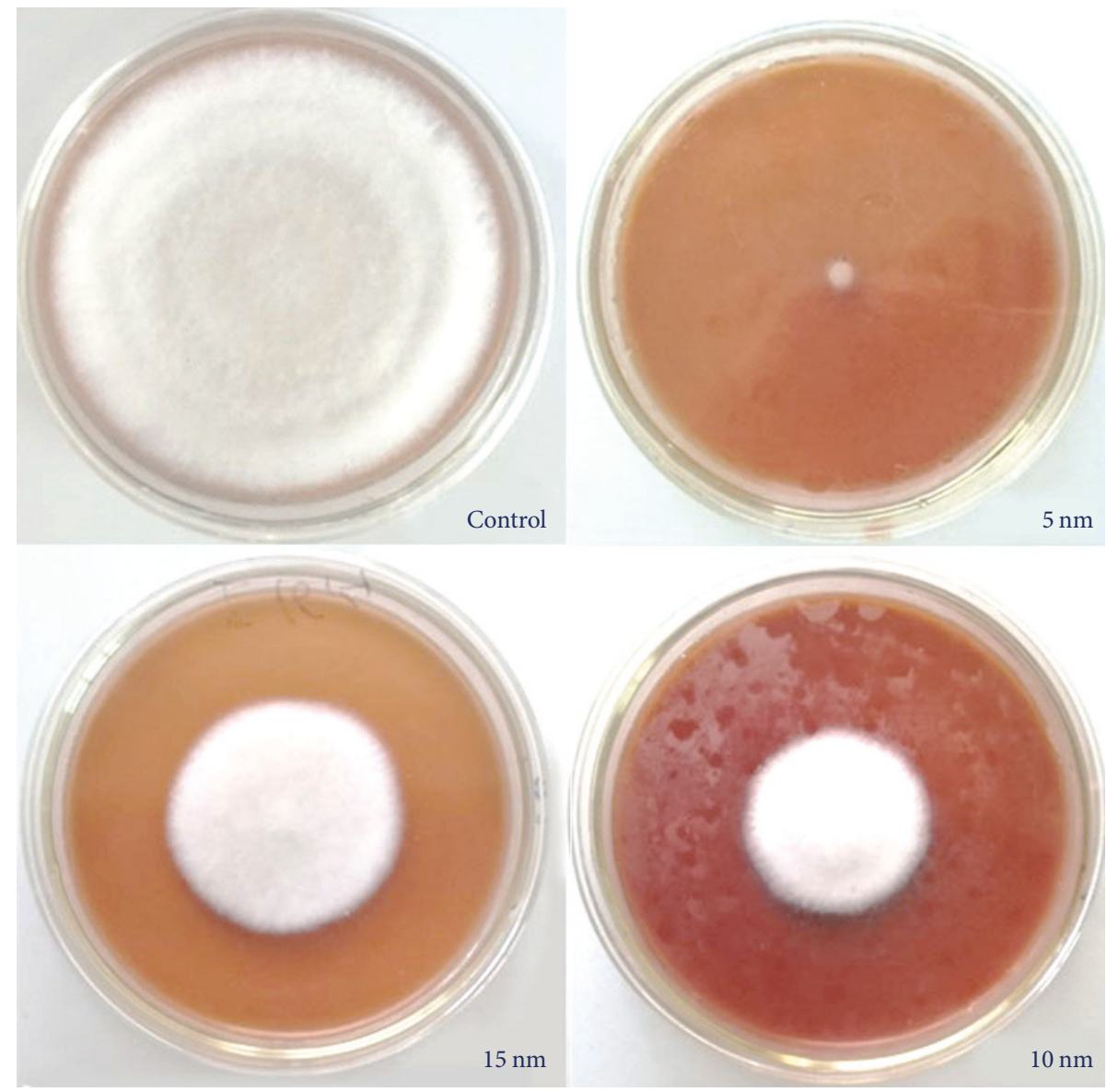

FIgURE 4: The growth of C. cassiicola after 192 hours of incubation on rubber-leaf extract media supplemented with AgNPs with different particle sizes. 


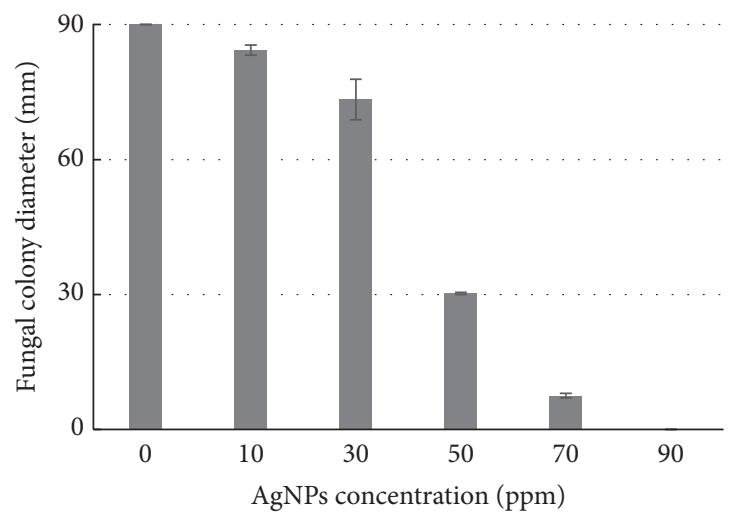

(a)

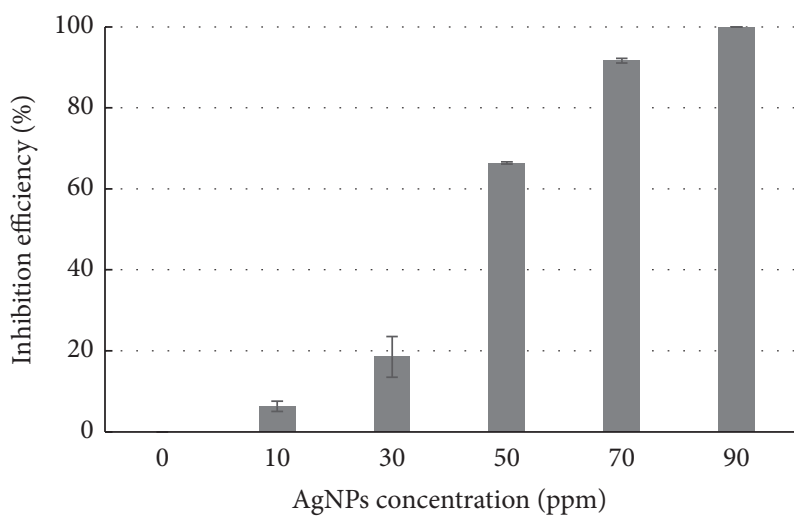

(b)

Figure 5: The antifungal activity against C. cassiicola of AgNPs $(10 \mathrm{~nm}$ ) at different concentration. (a) Diameter of fungal colony on rubber-leaf extract media after 192 hours of incubation and (b) inhibition efficiency.

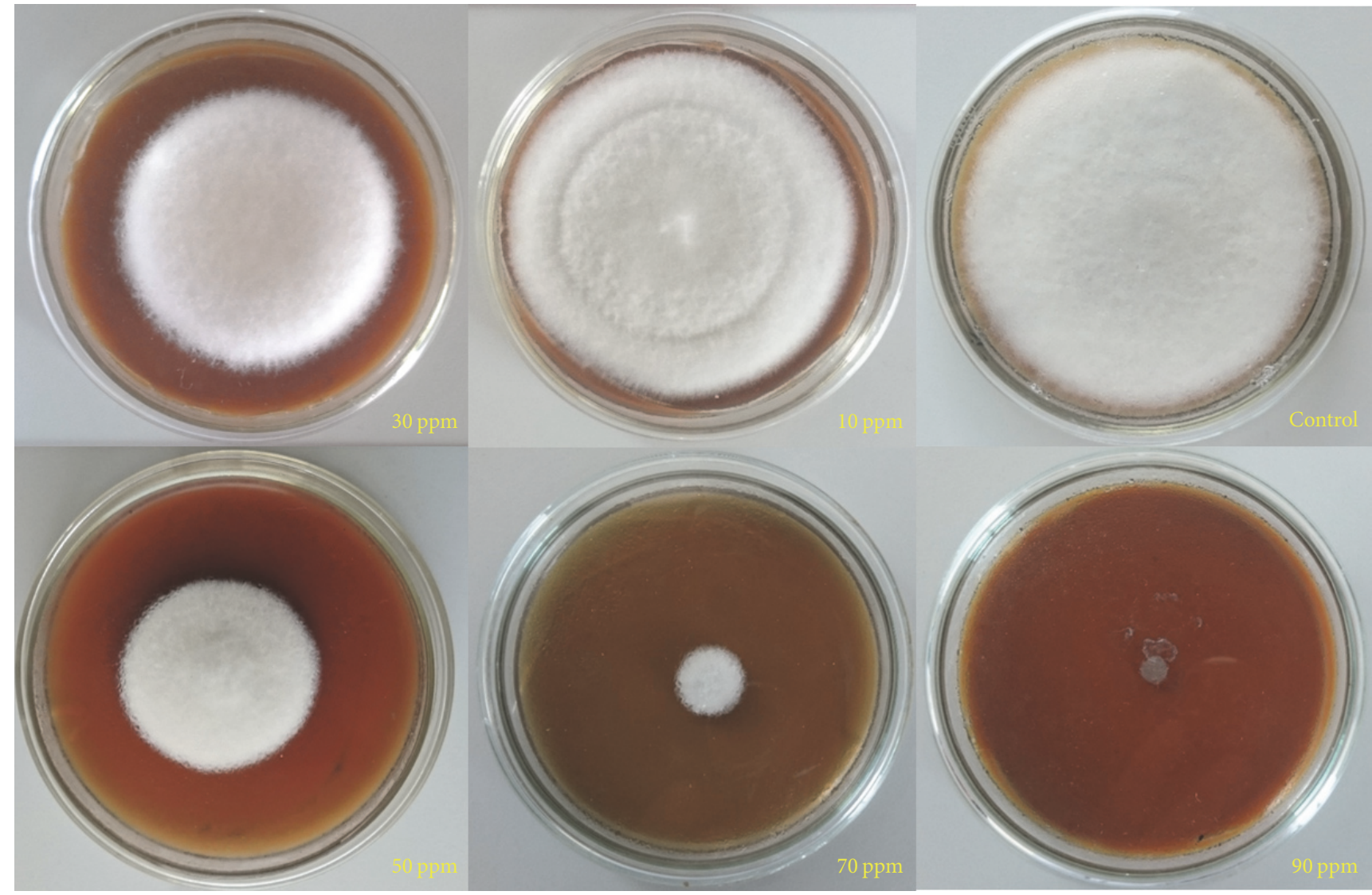

Figure 6: The growth of C. cassiicola after 216 hours of incubation on rubber-leaf extract media supplemented with different concentrations of AgNPs.

deformities in mycelial growth and the shape of hyphal walls. The layers of hyphal walls were also torn off on damaged hyphae at the fourth day and many hyphae were collapsed.

\section{Conclusions}

AgNPs with different particle sizes were successfully synthesized by gamma Co-60 irradiation method using chitosans with various Mw as stabilizers. The synthesized AgNPs/ chitosan products showed a strong inhibition effect against C. cassiicola on rubber-leaf extract media with the antifungal efficiency reaching $\sim 100 \%$ by the treatment of 50 ppm AgNPs with size of $5 \mathrm{~nm}$ or $90 \mathrm{ppm}$ AgNPs with size of $10 \mathrm{~nm}$. The foliar treatment with 5-12.5 ppm AgNPs solution strongly reduced the disease incidence of rubber trees as well as the disease incidence of rubber leaves infected by $C$. cassiicola 

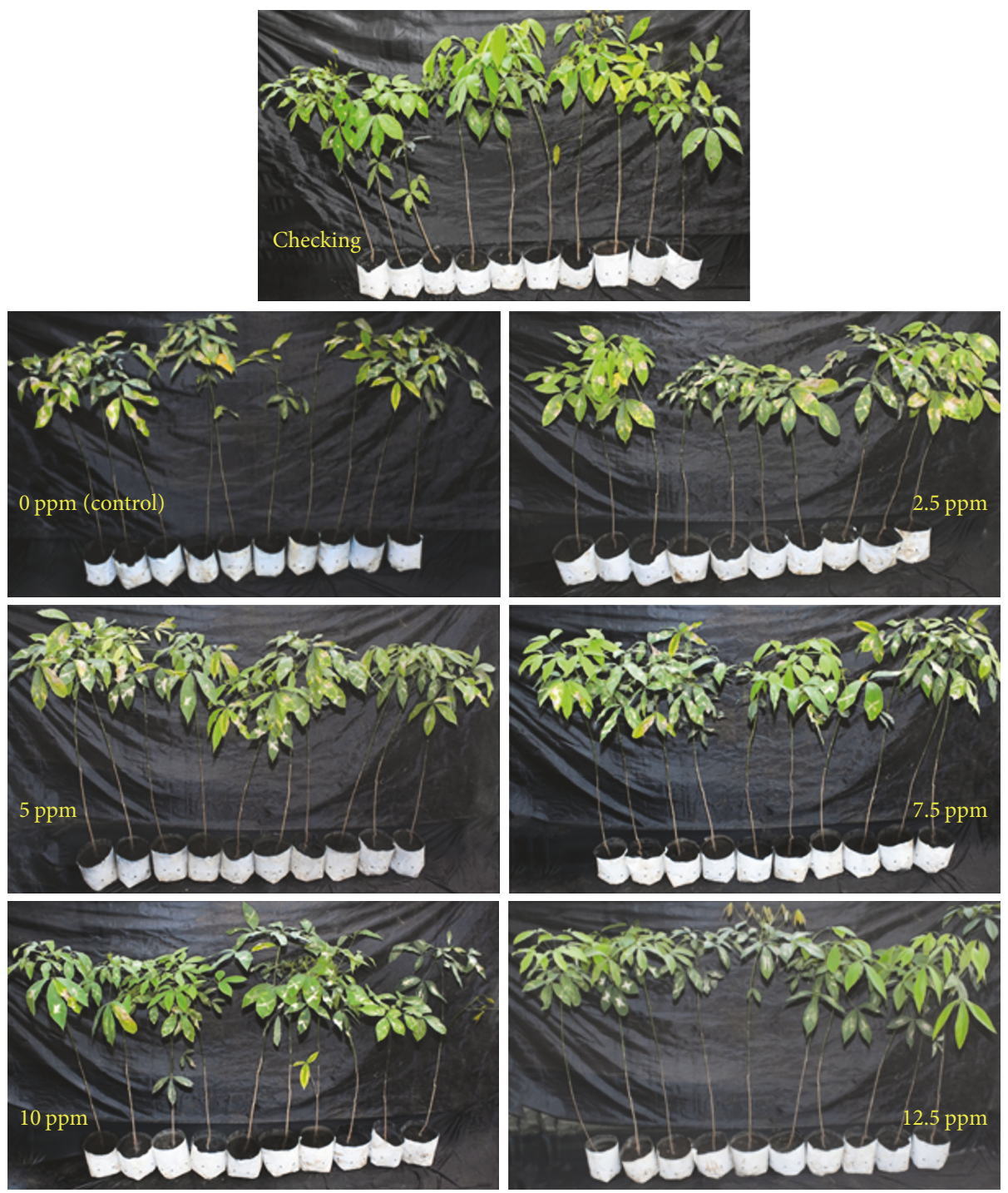

Figure 7: The rubber plants infected with C. cassiicola and treated with AgNPs (10 nm) at different concentration. Checking: plant without treating by fungal spore and AgNPs; control: plants infected by fungus spores before treating with only distilled water.
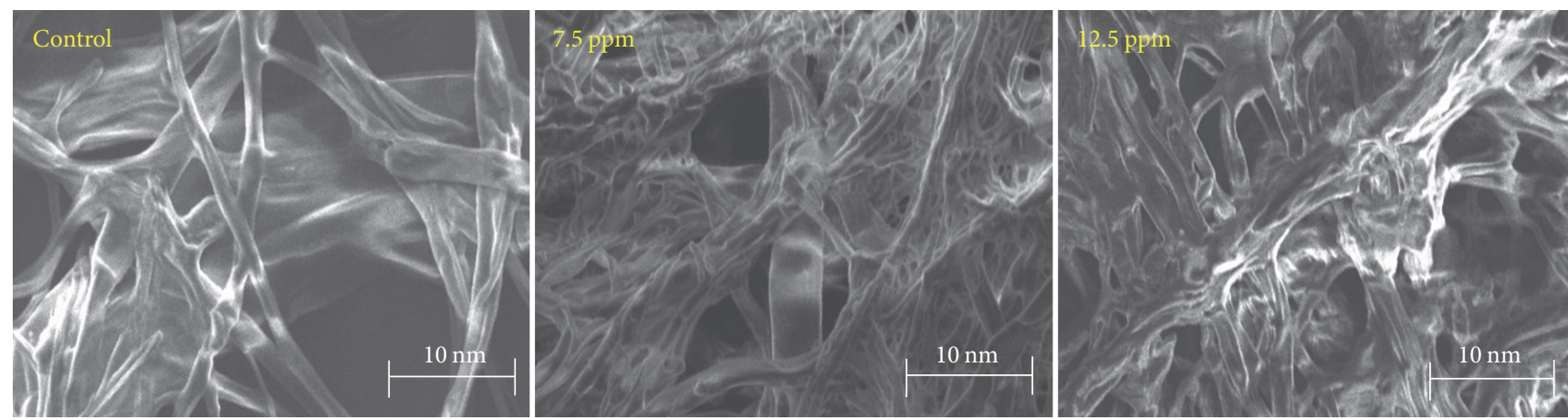

FIGURE 8: SEM images of hyphae of C. cassiicola treated with AgNPs. Fungal hyphae grown on rubber-leaf extract agar media plates were sprayed with either water as a control or equal volume of 7.5 and $12.5 \mathrm{ppm}$ of $10 \mathrm{~nm}$ AgNPs solution. Photos were taken at the fourth day after the treatment. 
fungus. Thus, AgNPs/chitosan synthesized by gamma Co60 irradiation method that is considered as a green method could be used as a potentially and effectively fungicidal product for controlling of C. cassiicola, a serious pathogen fungus on rubber trees.

\section{Conflicts of Interest}

The authors declare that they have no conflicts of interest.

\section{Acknowledgments}

This research was supported by Biotechnology Center of Ho Chi Minh City (Project no. NN01/16-17).

\section{References}

[1] M. Déon, B. Fumanal, S. Gimenez et al., "Diversity of the cassiicolin gene in corynespora cassiicola and relation with the pathogenicity in hevea brasiliensis," Fungal Biology, vol. 118, no. 1, pp. 32-47, 2014.

[2] C. K. Jayasinghe, T. H. P. S. Fernando, and U. M. S. Priyan ka, "Evaluation of fungicides in the management of Corynespora leaf fall disease of rubber in polybag nurseries," International Journal of Tropical Plant Disease, vol. 17, pp. 81-89, 1999.

[3] T. Saha, A. Kumar, A. S. Sreena et al., "Genetic variability of Corynespora cassiicola infecting Hevea brasiliensis isolated from the traditional rubber growing areas in India," Indian Journal Natural Rubber Research, vol. 13, pp. 1-10, 2000.

[4] L. Q. Luan, V. T. T. Ha, N. Nagasawa, T. Kume, F. Yoshii, and T. M. Nakanishi, "Biological effect of irradiated chitosan on plants in vitro," Biotechnology and Applied Biochemistry, vol. 41, no. 1, pp. 49-57, 2005.

[5] G. K. Agrawal, R. Rakwal, S. Tamogami, M. Yonekura, A. Kubo, and H. Saji, "Chitosan activates defense/stress response(s) in the leaves of Oryza sativa seedlings," Plant Physiology and Biochemistry, vol. 40, no. 12, pp. 1061-1069, 2002.

[6] N. I. Vasyukova, S. V. Zinov’eva, L. I. Il'inskaya et al., "Modulation of plant resistance to diseases by water-soluble chitosan," Applied Biochemistry and Microbiology, vol. 37, no. 1, pp. 103109, 2001.

[7] P. Vander, K. M. Våain, A. Domard, N. E. El Gueddari, and B. M. Moerschbacher, "Comparison of the ability of partially n-acetylated chitosans and chitooligosaccharides to elicit resistance reactions in wheat leaves," Plant Physiology, vol. 118, no. 4, pp. 1353-1359, 1998.

[8] K. Lamsal, S. W. Kim, J. H. Jung, Y. S. Kim, K. S. Kim, and Y. S. Lee, "Application of silver nanoparticles for the control of Colletotrichum species in vitro and pepper anthracnose disease in field," Mycobiology, vol. 39, no. 3, pp. 194-199, 2011.

[9] D. V. Phu, V. T. K. Lang, N. T. K. Lan et al., "Synthesis and antimicrobial effects of colloidal silver nanoparticles in chitosan by $\gamma$-irradiation," Journal of Experimental Nanoscience, vol. 5, no. 2, pp. 169-179, 2010.

[10] P. H. Diem, D. T. Thao, D. V. Phu et al., "Synthesis of Gold Nanoparticles Stabilized in Dextran Solution by Gamma Co-60 Ray Irradiation and Preparation of Gold Nanoparticles/Dextran Powder," Journal of Chemistry, vol. 2017, Article ID 6836375, 8 pages, 2017.

[11] T. Li, H. G. Park, and S.-H. Choi, " $\gamma$-Irradiation-induced preparation of Ag and Au nanoparticles and their characterizations,"
Materials Chemistry and Physics, vol. 105, no. 2-3, pp. 325-330, 2007.

[12] K. Naghavi, E. Saion, K. Rezaee, and W. M. M. Yunus, "Influence of dose on particle size of colloidal silver nanoparticles synthesized by gamma radiation," Radiation Physics and Chemistry, vol. 79, no. 12, pp. 1203-1208, 2010.

[13] P. Chen, L. Song, Y. Liu, and Y. E. Fang, "Synthesis of silver nanoparticles by $\gamma$-ray irradiation in acetic water solution containing chitosan," Radiation Physics and Chemistry, vol. 76, no. 7, pp. 1165-1168, 2007.

[14] N. Zahid, M. Maqbool, Y. Siddiqui, S. Manickam, and A. Ali, "Regulation of inducible enzymes and suppression of anthracnose using submicron chitosan dispersions," Scientia Horticulturae, vol. 193, pp. 381-388, 2015.

[15] L. Huang, M. L. Zhai, D. W. Long et al., "UV-induced synthesis, characterization and formation mechanism of silver nanoparticles in alkalic carboxymethylated chitosan solution," Journal of Nanoparticle Research, vol. 10, no. 7, pp. 1193-1202, 2008.

[16] R. Yoksan and S. Chirachanchai, "Silver nanoparticles dispersing in chitosan solution: preparation by $\gamma$-ray irradiation and their antimicrobial activities," Materials Chemistry and Physics, vol. 115, no. 1, pp. 296-302, 2009.

[17] C. Carlson, S. M. Hussein, A. M. Schrand et al., "Unique cellular interaction of silver nanoparticles: size-dependent generation of reactive oxygen species," The Journal of Physical Chemistry B, vol. 112, no. 43, pp. 13608-13619, 2008.

[18] G. Franci, A. Falanga, S. Galdiero et al., "Silver nanoparticles as potential antibacterial agents," Molecules, vol. 20, no. 5, pp. 8856-8874, 2015.

[19] K. Kim, W. S. Sung, B. K. Suh et al., "Antifungal activity and mode of action of silver nano-particles on Candida albicans," BioMetals, vol. 22, no. 2, pp. 235-242, 2009.

[20] A. Nasrollahi, K. Pourshamsian, and P. Mansourkiaee, "Antifungal activity of silver nanoparticles on some of fungi," International Journal of Nano Dimension, vol. 1, pp. 233-239, 2011.

[21] S. W. Kim, J. H. Jung, K. Lamsal, Y. S. Kim, J. S. Min, and Y. S. Lee, "Antifungal effects of silver nanoparticles (AgNPs) against various plant pathogenic fungi," Mycobiology, vol. 40, no. 1, pp. 53-58, 2012.

[22] K.-H. Cho, J.-E. Park, T. Osaka, and S.-G. Park, “The study of antimicrobial activity and preservative effects of nanosilver ingredient," Electrochimica Acta, vol. 51, no. 5, pp. 956-960, 2005.

[23] Y. K. Jo, B. H. Kim, and G. Jung, "Antifungal activity of silver ions and nanoparticles on phytopathogenic fungi," Plant Disease, vol. 93, no. 10, pp. 1037-1043, 2009.

[24] A. Panacek, L. Kvítek, and R. Prucek, "Silver colloid nanoparticles: synthesis, characterization, and their antibacterial activity," The Journal of Physical Chemistry B, vol. 110, no. 33, pp. 1624816253, 2006.

[25] S. Shrivastava, T. Bera, A. Roy, G. Singh, P. Ramachandrarao, and D. Dash, "Characterization of enhanced antibacterial effects of novel silver nanoparticles," Nanotechnology, vol. 18, no. 22, Article ID 225103, 2007. 


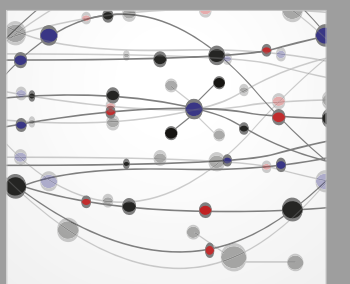

The Scientific World Journal
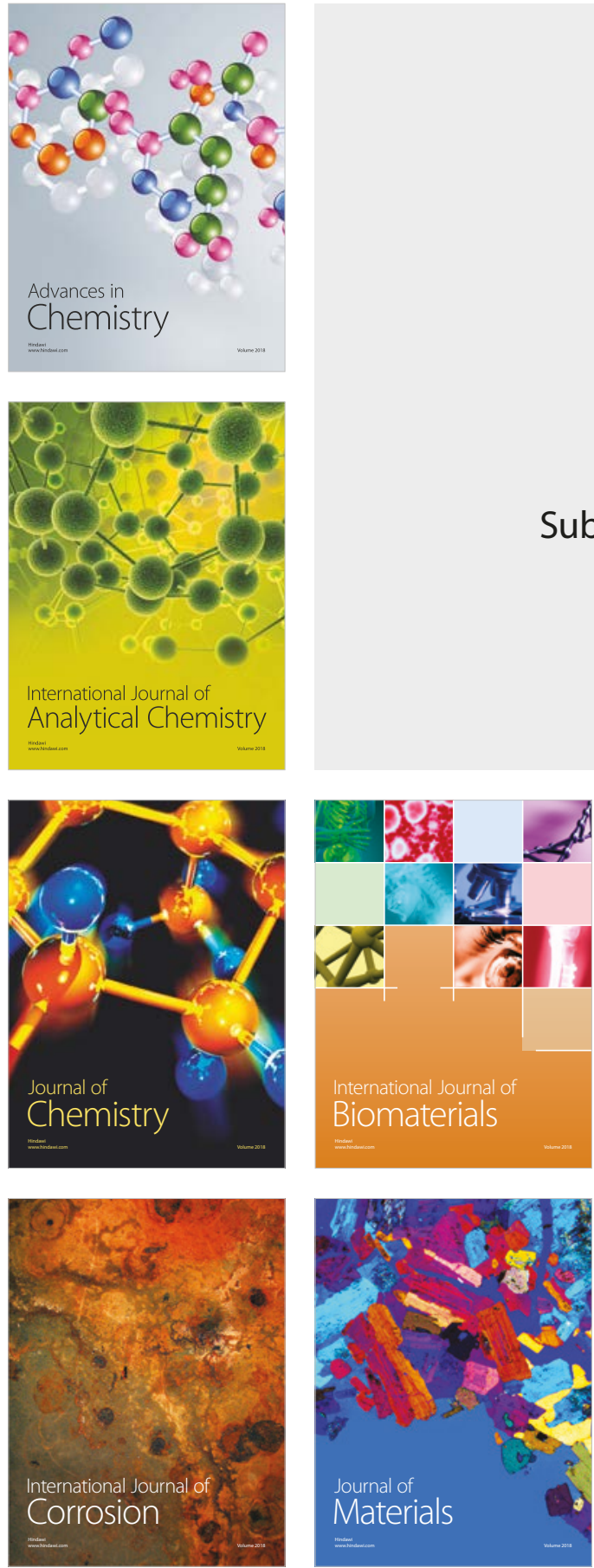

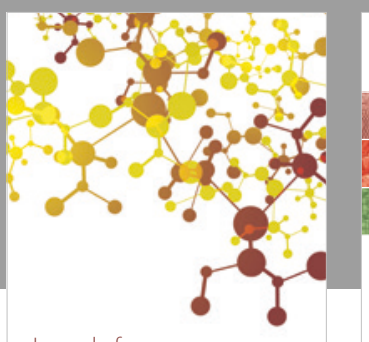

Journal of

Applied Chemistry
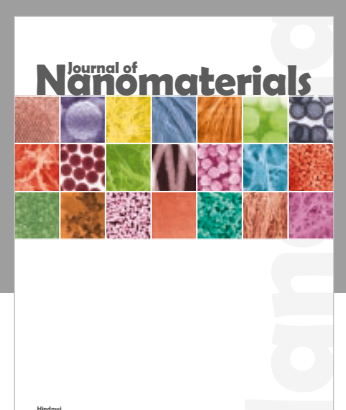

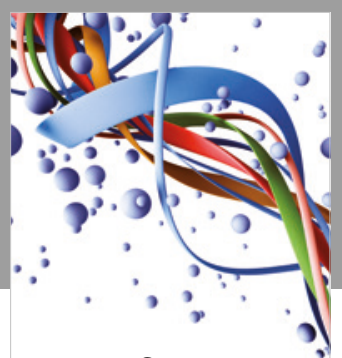

Scientifica

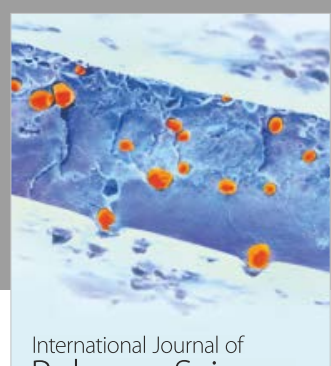

Polymer Science

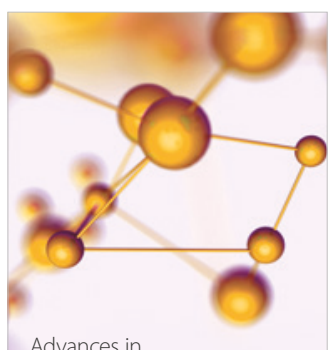

Physical Chemistry
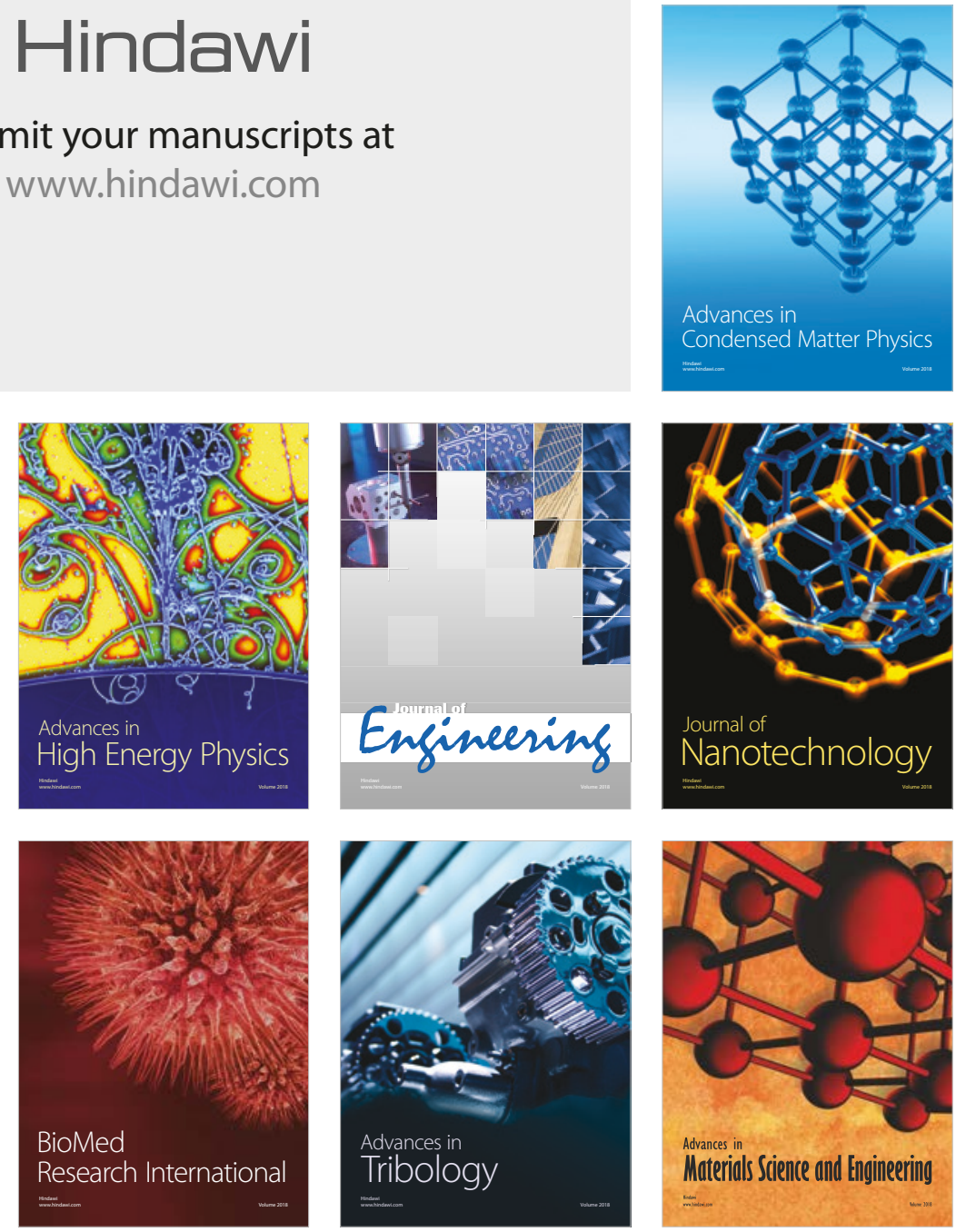